\title{
THE FAILURE OF PLANNING ENDEVOUR IN NORTH EAST BORDER AREA OF SERBIA TOWARDS BULGARIA
}

DOI: http://dx.doi.org/10.18509/GBP.2017.13

UDC: 711:911(497.11-192:497.2)

\section{Dejan Djordjević ${ }^{1}$ \\ Nevena Vasiljević}

${ }^{1}$ Department of Spatial Planning, Faculty of Geography University of Belgrade, Studentski trg 3/III, 11000 Belgrade, Serbia

${ }^{2}$ Department of Landscape Arhictteture and Horticulture, Faculty of Forestry University of Belgrade, Kneza Višeslava, 11000 Belgrade, Serbia

\begin{abstract}
With the transition, spatial planning was supposed to mitigate the negative effects of the new player - market to the public interest. But, seems like our planning didn't find the mechanisms to mitigate those effects created by the market inside it. Planning institutions in pretransitional period were exclusively in public sector. We now have on one side, some big planning institution, partially financed from the state's budget usually with the monopoly over elaboration of one group of plans and on the other side, smaller ones which are being privatized. Both are thrown to the market and are trying to acquire as much engagements as possible in order to secure enough financing. They are producing more plans for less money in a shorter period of time. As a result, these former public agents diverted by the new hostile conditions given by undeveloped market and neoliberal environment are still presenting traditional rigid planning model, deterministic and inflexible, with fixed land use parameters and regulations. Seems like the turbulent times in which the most important task is to survive didn't give them a chance to develop and to introduce more innovative and novel models in view of participative, strategic and action plan oriented planning. The failure of planning enterprise to achieve at least some balance in regional inequity is clearly visible in peripheral, i.e. border areas. The paper discuss the main objectives and planning concepts in various overlapping planning documents on national, regional and local levels elaborated for Timočka krajina, a border region situated in NE Serbia towards a frontier to Bulgaria, and the obvious gap between planning optimism and accurate demographic, social and economic decline of the region, despite both local and European based, mostly cross border related projects and initiatives.
\end{abstract}

Key words: spatial planning, critical geography, plan evaluation, effectiveness, border areas, Serbia.

\section{INTRODUCTION: SERBIAN PLANNING IN TRANSITION}

In almost three decades that have elapsed since the overthrow of state socialism (or communism) in Central and Eastern Europe (CEE), substantial changes have occurred in the nature, role and functioning of government and other institutions involved in spatial development and urban policy [8]. Urban planning and policy responses of localities have 
been quite diverse, reacting to specific and often dramatic conditions: political democratization, reintroduction of market principles, the state's fiscal crisis, massive privatization, commercialization, discontinuation of "welfare state" programs, and intensified international financial transactions and investments in urban areas [10]. The new circumstances have prompted not only new institutions but also a "new notion of planning" that strives to regain its legitimacy, become more flexible, and adapt to the new economic and political circumstances [2]). In those dynamics, an idiosyncratic mix of old, new and innovative practices interjects into the transforming reality [4]

The transition of societies and cities from communist to post-communist, therefore, involves - among other things - new systems of government (or governance); new legal, constitutional and institutional frameworks; new economic order; new rules of social integration; and new policy choices for privatization and redistribution of public assets [1]. The theory of transition is rooted in the democratization theory that views transition as primarily a political process. Transition specifically of urban phenomena and processes, too, is viewed as essentially political and economic, and perhaps not distinguishable from the transition in general [11].

The case of former Yugoslavia and present Serbia illustrates well the changes that a planning system undergoes in response to the changing political regime, socio-economic system and institutions. While the planning systems in other Central and Eastern European countries have been under transition during the post Second World War and the more recent post-communist period, the Serbian case is particularly heavy in societal dynamics and scope that went beyond what could be considered a typical experience and context of a communist or a post-communist CEE country [5]. The more extreme variations in how planning profession and practice operated in former Yugoslavia and how they responded to the societal circumstances from 1989 on offer a rich set of observations that would point to the relationships between planning law and its broader context on one hand and planning practice on the other hand. The lingering transition (or what Thomas [9] terms "the moment of discontinuity"), which in Serbia seems to have been more complex and less predictable than in other post-communist countries in Europe, also allows for an extended time period for studying the processes and issues that underlie the formation of a new planning system.

Local (municipal) spatial plans, together with spatial plans for areas of special use, are being produced more than ever. Accordingly to the current Law, these plans determine the starting point, the spatial development objectives and land use, organization and protection rules of the planning area. In theory, the number of municipal spatial plans and general plans for municipal centres, both sorts having strategic developmental aspirations can climb up to 150 each. For now they are unique wheals that are turning in Serbia's planning and the main source of our planners' existence. They are accommodating the quantitative development of planning in Serbia but most of them are not showing any shift in methodology which would enable the planning to respond quickly to changes occurring in all societal domains but foremost in the economic sphere. They are backed up by poorly assessed economic and social needs development analyses (sometimes even badly assessed spatial dimension), so that they come down to the physical/geographic definition of the often illusory planning objectives, solutions and propositions. Without applying integrative planning method, more ex post and ex continuo instead of prevailing ex ante evaluation these plans will hardly contribute to quality improvement or more importantly to a prosperous development of the planning area. There lays the chief indifference of the authorities and citizens to participate in elaboration of such plans, let 
alone be guided by them. The current planning practice is therefore, predominantly planners' centred; implying that it is the planner who identifies the problems and seeks for planning alternatives. There is little or no room for different interests and ideas, intersectoral coordination and synchronization or partnership between public and private actors. Consequently, there is hardly any room for various stakeholders and shareholders to take part in the planning process and the ensuing implementation phase. Stojkov, Subotic and Djordjevic [7] are characterizing such a system of spatial planning as: 1) More or less developed spatial-geographical environmental system of criteria, i.e. a way of thinking on the spatial conditions for locating networks and development; Certain crucial mistakes of planners, which we encounter from time to time still do not discredit this planning dimension; 2) Utterly undeveloped and inadequately established assessment and evaluation system of the financial-economic feasibility of planned solutions and an even more serious problem of the complete lack of an passable economic development strategy, without which the spatial plan is placed in an unreal economic space and time; 3) Not of lesser significance is the social system development out of which should derive the idea on the needs, values and goals of a social community for which we make plans. This system, as yet, has been subjected to a mere improvisation in plans (urbanisation, housing, renewal, public services, special assets);

How can we explain this failure of spatial planning and which are the pillars we should build to make it more developed and more stable for turbulent times that could come in the future? Furthermore, what are the consequences for trans-border cooperation, in this case, with Bulgaria?

\section{NATIONAL CASE STUDY: THE BRIEF SUMMARY OF THE SPATIAL DEVELOPMENT PLANNING OF THE NORTH-EASTERN BORDER ZONE OF SERBIA IN THE DIRECTION TO BULGARIA}

It has been more than twenty years since the latest scientific paper, which was related to the spatial planning of the border zone in the direction of Bulgaria was published at the Department of Spatial Planning. In spite of the fact that there have been contacts meanwhile, as well as the attempts to establish the joint projects and institutionalize the cooperation in the domain of spatial development planning, the cooperation has been random and temporary until the present moment, and it extended to the very limited areas in the spatial sense. In the most cases the cooperation was established indirectly. For instance, the Iron Gate project (from 2001 to 2002) was financed by the German Government, with the participation of experts from Romania, Bulgaria and Serbia, and it was continued under the new name Cultural Paths of the Danube Region, but the echo of it among the Serbian professionals and politicians was insignificant.

The border zone of north-eastern Serbia in the direction to Bulgaria is to the greatest extent determined by the natural borders - orohydrographic watershed of the Balkan Mountains. The only pass through the mountain barrier (and the best connection between Serbia and Bulgaria) is the narrow river valley of Danube, which based on the contemporary nomenclature, is the Trans-European Corridor VII. Aside from the abovementioned transversal direction East-West, the border zone of Serbia in the direction to Bulgaria is economically underdeveloped, with small access to the transport services, with the extreme depopulation trends, with all negative indicators regarding the demographic structure, and with the high percentage of the forest land in the total land area. The cattle breeding is dominant in agriculture, and the greatest part of the industry, established in the time of socialism, is either insolvent or in the process of transition, 
closed due to malpractices and corruption, or in the state of bankruptcy. The unemployment rate is growing, as well as the apathy among the population, and there are fewer and fewer vehicles on the roads of Timok Region.

The peripheral location and underdevelopment of the area was reported and de facto existed also in socialism. The plans adopted at the time - such as the Regional Spatial Plan of Timok Region dated from 1976 - apart from stating agriculture as the main chance for the development, emphasized the importance of industrial development (areas of Bor, Majdanpek, Negotin, Zaječar, etc.), energy (hydro-power plants Đerdap I and II), and, to a smaller extent, the significance of tourism. In the early 1990s the great crisis occurred - the collapse of the country, sanctions, civil war in the former Yugoslavia. The measure and indicator of the condition regarding the spatial development planning was the Spatial Plan of the Republic of Serbia, adopted in 1996. Although it was vitally conceptually closed, without solutions such as cross-border cooperation, it emphasized the need of the construction of the above-mentioned highway infrastructure, of making the entire territory more available, of reversing the above-mentioned negative trends, of the faster development of tourism (given the current natural potentials and historical-cultural monuments), as well as the importance of the creation of a wide range of the regional spatial plans, and the plans aimed for the special purpose areas - for infrastructure corridors, for the areas where the mines and mineral resources are extracted, for the drainage basin of the man-made water retentions, for the national parks and other areas of exceptional natural values, for the important historical-cultural monuments, tourism areas, etc. Up to the year 2000, almost nothing was done regarding the implementation of such an important strategic document. Instead, there was bombing in 1999, and some kind of democratic revolution occurred in 2000.

Since the year 2000, a new, latest phase, regarding the spatial development planning of both Serbia and border zone in the direction of Bulgaria, has begun. This phase, let us call it transitional, inter alia, is characterised by the complete dominance of the private interest over the public one - so-called "urbanism of investments and planning", and Serbia is not a peculiar case of such a practice, as it is to a smaller or greater extent present in all countries which have undergone the transition process, or they are still undergoing it. The domination of the market in the process of development and small role and importance of the spatial planning serve as the mirror of the power and influence of the state apparatus, which has done almost nothing to establish the social balance, economic prosperity, regional balance, etc., but to sell off at extremely low prices the state/public property. There are widening economic and social gaps, the contrasts between the rich and poor are becoming greater and greater, and in the regional sense, the differences between the more developed North of the Republic of Serbia (in combination with Belgrade) and South are more and more striking. The weakened state apparatus, however, has not initiated the process of decentralisation due to several reasons (politics, tradition, negative historical values and experiences, etc), and the direct result of it is the fact that the spatial planning of the border zone of Serbia in the direction to Bulgaria is almost entirely in the hands of state apparatus. The lack of money and responsibilities at the local level, as well as the fact that the regional level of the management does not exist, has resulted in the condition in which there is only one planning instrument - state planning, which will be briefly described in the following lines.

In addition to the above-mentioned spatial plans for the special purpose areas, which are made for the spatially limited zones for the protection of the hydro-accumulations, natural and historical-cultural monuments, as well as the local-municipal plans which, to 
the great extent, based on the principle of hierarchy, rewrite and elaborate on the solutions from the plans of the higher rank, two spatial plans of key importance to the spatial development of the north-eastern border zone of Serbia in the direction to Bulgaria were made. Both of them are of the regional importance and are related to the areas of Serbia towards Bulgaria, to the northward of the Nišava River - Regional Spatial Plan of Timok Region and spatial plan for the direction of the pass through the oro-hydrographic barrier which divides Serbia and Bulgaria: Spatial plan for the spatial purpose areas for the corridor VII, which encompasses the Danube Region, the solutions of which are relevant for our survey only in the zone around Đerdap, but it should stem from the international project (in the sense of the elaboration) entitled "DONAU REGIONEN". The first two plans are made by the Republic of Serbia individually, whereas the fourth one is of the international prominence, regarding both the participants and financing. The common feature of all three plans is the fact that the Republic Agency for Spatial Planning of the Republic of Serbia (closed in 2015) played the main role in the spatial planning in Serbia, but it was practically their only real common denominator, in spite of some declarative claims in the, let us call them, "Serbian" spatial plans. The first two above-mentioned plans, in brief, are characterized by the excessive optimism and reliance on the European development funds that are not available yet, which is in stark contrast with: a) economical and social situation in the country, b) the total investment environment and with c) trends in the close and further vicinity.

Without going into detail of the spatial plans, it is sufficient to illustrate the abovementioned claim with the scenarios of development. Thus, there are three anticipated scenarios for Timok Region up to the year 2025, which, consequently, anticipate the integration into the European Union in 2015 (with the projected GDP of Timok Region per capita equivalent to 4,797 euros), the "Balkan Tiger" scenario, which implies the accelerated EU accession (up to the year 2012, with the projected GDP of Timok Region per capita equivalent to 8, 316 euros), and last one, so-called pessimistic scenario, more modest, predicting full membership in EU in 2020 and GDP per capita equivalent to 3, 323 euros. As, by our estimates, neither by the third projection the satisfactory development of Serbia by 2025 will be reached, the fourth projection, implying the annual growth of GDP equivalent to $8.2 \%$, which means the GDP of Timok Region per capita equivalent to 15,000 euros, was made. Even the pessimistic scenario or the scenario of the low level of growth, from the current 2,000 euros, to 3, 323 euros per capita, which would imply reaching of the current GDP of Serbia per capita, equivalent to 3, 354 euros (all of these assumptions are based on: Regional Spatial Plan of Timok Region - Program for Creation, Republic Agency for Spatial Planning of the Republic of Serbia, 2007, p. 65). The similar ones, although somewhat more realistic planning assumptions can be found in the Regional Spatial Plan of the Municipalities of South Morava Region 20062021 [6]. Based on such unrealistic scenarios, the planning solutions which are necessary equally unrealistic are defined, so there is no point in stating them. Such populist spatial planning policy is the result of the generally unrealistic policies of state in the current period, which is almost entirely based on two premises: that in the very short period of time we would get incredibly high quantity of money, which would enable us to solve the problems accumulated for years (including the problems regarding the spatial planning), and that we would be able, in addition to this gift, to sell off all our natural and other resources at very high price to the foreign investors.

The most methodologically elaborated, the most systematically done and the most financed project which refers to the border zone of Serbia in the direction to Serbia is so- 
called DONAU REGIONEN, which is implemented under the auspices of the EU. Although it has its faults, due to the shortage of better, and, in the first place, feasible projects, it deserves to be presented as the example, and, why not, as the model of the way in which the spatial development should be planned under the very unfavorable conditions in the early 21 st century.

\section{INTERNATIONAL CASE STUDY: DONAUREGIONEN}

The regions located in close vicinity to the Danube recognizing the potential benefits which can come out of the elimination of political barriers, liberalization of economic relations and opening of the transcontinental water route Rhine-Main-Danube established ARGE DONAULÄNDER, the Working Unity of the Danube Region Countries. The aim was, and still is, to initiate and synchronize the co-operation among the countries of the Danube Region by organizing their development and location throughout the region, with a special focus on the development of regions, towns and ports economically lagging behind. Within the scope of the Working Unity, in the framework of the Working Group for Regional Arrangement and Spatial Planning, the Concept of Co-operation among the Regions, Towns and Ports along the Danube River was prepared. The preparation of the concept led to the elaboration of a complex methodology of joint analytic and planning activities. The concept supposes that the phases of the whole long-term cooperation concept are as follows:1) Summary Evaluation of the Development Potential in the Danubian Area; 2)Typology and selection of development centers in the Danubian Area; 3) Danube River Basin spatial arrangement concept; 4) Set of assertion tools for project plans implementation in the Danubian Area.

The project activities supposed specification of the project methodology, an update of the meta-information data catalogue system; General Development Schemes focused on Natural Conditions, Settlement Structure, Transport and Infrastructure and Economic Structure of Danube NUTS3 regions elaborated with participation of all partners, but partners from Bulgaria, Hungary, Serbia and Slovakia had the overall responsibilities for the final completion of each of these latter. After the all mentioned General Development Schemes were elaborated, basic conclusions were made: 1) Danube region has a good quality natural potential; 2) Settlement structure is insufficiently developed especially concerning centers of regional importance; 3) Accessibility in the Danube area regions is poor. Lack of Danube crossings and it is difficult to access transport networks of European importance; 4) Danube region has significant sources of energetic and water management potential; 5) Regional economic development is highly differentiated, serious disparities exist between metropolis and the rest of area, as well as between middle Danube area (SK, HU) and lower Danube area (SR, RO, BG); 6) After previous political and infrastructure barriers the potential cooperation of crossborder and crossdanube regions, towns and ports remains unused.

In order to specify the internal hierarchy of Cross Danube Regions between those representing the metropolitan growth poles and the ones representing the potential growth areas of regional importance, the ARGEDONAU Subregions were proposed but both are still considered as preliminary. The concept itself as well as the process of the description of the ARGEDONAU Subregions, Cross Danube Regions and the strategy will be the subject of the Donauregionen+ project, which is currently in the preparatory phase. 


\section{CONCLUDING REMARKS}

With the transition, planning was supposed to mitigate the negative effects of the new player - market to the public interest. But, seems like our planning didn't find the mechanisms to mitigate those effects created by the market inside it. Planning institutions in pretransitional period were exclusively in public sector. We now have on one side, some big planning institution, partially financed from the state's budget usually with the monopoly over elaboration of one group of plans and on the other side, smaller ones which are being privatized. Both are thrown to the market and are trying to acquire as much engagements as possible in order to secure enough financing. They are producing more plans for less money in a shorter period of time. As a result, these former public agents diverted by the new hostile conditions given by undeveloped market and neoliberal environment are still presenting traditional rigid planning model, deterministic and inflexible, with fixed land use parameters and regulations. The other problem lays in insufficient recognition of importance and purpose of planning among politicians and the lack of persuading voices and pressure coming from the profession, as well as in the loss of its legitimacy. To illustrate the confusion and neglect politicians express when planning is concerned we are informing that spatial planning was situated first under the Ministry of Capital Investments, than under the Ministry of Infrastructure, and at the present within the Ministry of Environment.

Democratic and economic reforms are not only critical to an overall successful transformation in Serbia, but also inextricably linked to achieving successes in each reform area which also includes planning. Democratic processes are an essential component of Serbia's economic growth and stability, and economic growth is essential to create the conditions for a continuing stable democracy. Reform in the social sector is also necessary in order to secure their better performance. When Serbia as a whole ensures safer environment it is certain that our planning will be able to redefine its priorities and to concentrate on the development of coherent theoretical and methodological framework as a main goal. This can give more appropriate meaning and contents to integrative approach, sustainability, subsidiarity, efficiency, cooperation, communication, coordination and networks which are currently recognized as empty concepts in our planning. Hopefully, the system will be strong and stable enough not to collapse again in case of another "earthquake" and able to continue due to inertia with the fewest casualties possible. As long as the planning system is not stabilized, the weak attempts to correct the social, economic and spatial differences by using the state policies will not have a wide impact or results, and the typical example of it is the north-eastern border zone of Serbia in the direction to Bulgaria. It is logical to strengthen the cross-border cooperation, in spite of the future state-social status of Serbia, within or on the edge of the EU, since it is dictated by the common sense and professionalism. Owning to the fact that the global economic crisis will not last forever, the financial assets, which are the necessary prerequisites for each spatial development planning, will be, undoubtedly, greater than today, so spending and distribution will be more fair and efficient compared to the present situation. Some changes are still to be made in the concept and approach to the planning of the spatial development, so that they become feasible, closer to the real needs and priorities of the citizens and less stereotype, less prescribed by the "Big Brother", less general, less declarative and more meaningful - such as the Strategy of the Spatial Development of Serbia, which is being prepared. However, one factor, which neither methodology, the EU, nor money cannot altered remains: the catastrophic demographic 
situation in the border zone of Serbia in the direction to Bulgaria. This factor will be the stumbling stone for all development plans in the future.

\section{References}

[1] Harloe M. Cities in the transition. U: Andrusz G, Harloe M, Szelenyi I (eds) Cities after socialism - Urban and regional change and conflict in post-socialist societies. Oxford: Blackwell Publishers, 1996.

[2] Kornai J. Reforming the welfare state in postsocialist societies (editorial). World Development 25, p.p.1183-1185, 1997.

[3] Ministry of Construction and Regional Development of the Slovak Republic.The Spatial Development of Interregional Co-operation in the Danube Space, DONAUREGIONEN, Bratislava. 2008.

[4] Nedović-Budić Z. Adjustment of planning practice to the new Eastern and Central European context. Journal of the American Planning Association 67, 38-52, 2001.

[5] Nedović-Budić Z. \& Cavrić, B. Waves of Planning: Framework for Studying the Evolution of Planning Systems and Empirical Insights from Serbia and Montenegro. Planning Perspectives 21, p.p. 393-425, 2006.

[6] RAPP. Regionalni prostorni plan Timočke krajine, Beograd, Srbija, 2007.

[7] Stojkov B. \& Subotic S. \& Djordjevic D. New trends in planning theory and practice in Serbia. alfa SPECTRA - Central European Journal of Architecture and Planning FA STU 2/2004, p.p.9-15, 2004.

[8] Taşan-Kok T. Budapest, Istanbul, and Warsaw - Institutional and spatial change. Delft: Eburon, 2004.

[9] Thomas M. Thinking about planning in the transitional countries of Central and Eastern Europe. International planning studies 3, p.p.321-333, 1998.

[10] Tsenkova S. \& Nedović-Budić Z. Urban Mosaic of Post-socialist Europe - Space, Institutions and Policy. Heidelberg: Springer, 2006.

[11] Wu F. Transitional cities (Commentary). Environment and Planning A 35, p.p.13311338, 2003. 